\title{
Child Maltreatment and Academic Performance of Senior Secondary School Students in Ibadan, Nigeria
}

\author{
Adejobi A. O. $^{1}$ \\ Osonwa, O. $\mathrm{K}^{2}$ \\ Iyam, M.A ${ }^{3}$ \\ Udonwa, R.E ${ }^{4}$ \\ Osonwa, R.H $H^{5}$ \\ 1. Education Department, University of Ibadan, Nigeria. \\ 2. Sociology Department, University of Calabar, Nigeria. \\ 3. Vocational Education Department, University of Calabar, Nigeria. \\ 4. Home Economics Department, University of Calabar, Nigeria. \\ 5. Guidance and Counseling Department, University of Calabar, Nigeria.
}

\section{Doi:10.5901/jesr.2013.v3n2p175}

\section{Abstract}

This research was carried out to examine the effect of child maltreatment on academic performance of Senior Secondary School students in Ibadan, Nigeria. The Questionnaire was the instrument of data collection, administered to five hundred and twelve students selected randomly in two local government areas. A hypothesis that "there is no significant relationship between child maltreatment and academic performance" was formulated. This was tested using multiple regression analysis and the result indicated that there is significant relationship between child maltreatment and academic performance. It is recommended among others that the government should intensify efforts towards eradication of poverty among the populace, so as to enable parents have enough capital to provide for their children. Also, single parenthood should be discouraged as it exposes children to all kinds of maltreatment.

Keywords: Academic, Child, Maltreatment, Performance.

\section{Introduction}

A person's education is closely linked to his life chances, income and well being (Battle and Lewis 2002). Therefore, it is important to have a clear understanding of what benefits or hinders one's educational attainment. Education generally is seen as an agent of socialization and integration of a child or an adult into the norms of the society. Equally it is the process of transmitting the culture of a society to the learners in a formalized setting. Unequivocally, it is seen as the bedrock of any nation. In order to ensure the growth and development of a nation, it becomes imperative for right policy to be in place to allow for effective planning and execution of educational programmes.

Academic performance (most especially of senior secondary school students) has been largely associated with many factors. Most student in senior secondary schools in Nigeria are daily confronted with challenges of coping with academics under serious emotional strains occasioned by long walk to school, poor school environment, and been taught by unmotivated teachers. Couple with this, is an uncooperative - to - study attitude of parents who more often toil to provide for the needs of the family. These would definitely not augur well for academic success.

The word child maltreatment is sometimes used as child abuse. It is any form of physical, psychological, social, emotional and sexual maltreatment of a child whereby the survival, safety, self esteem, growth and development of the child are endangered (Alokan and Bimbola, 2010). The term child maltreatment subsumes many different conditions. It involves acts of omission or commission by a parent or guardian that are judged by a mixture of community values and professional expertise to be inappropriate and damaging to the child. 
According to Wikipedia (2009), most child maltreatment or abuse occurs in a child's home, with a smaller amount occurring in the organizations, schools or communities the child interacts with.

One negative aspect of family's life is the effect of domestic violence on children, either as witness to, or victims of conflict which is determined by inter-parental relationship child could be severely traumatized by witnessing domestic violence or themselves being victims of this violence. Domestic violence simply refers to violence between adult intimate partners. It is also said that domestic violence is a pattern of assaultive and coercive behaviours, including physical, sexual and psychological, as well as, economic coercion, that adults or adolescents use against their intimate partners. Today domestic violence is not recognized as a serious societal problem in Nigeria (Imtionde, Aluede and Oboite, 2009). Yet, children in families in which such violence occurs have remained largely invisible as victims. Children who live in households with domestic violence are said to be at higher risk for maladjustment than children who do not live with such violence. Exposure to domestic violence can have serious negative effect on children. Such effects may include behavioural problem such as aggression, phobias, insomnia, low-self esteem, and depression, low level of social competence, poor academic performance and low level of problem solving skills (Osofsky, 1995; Margolin and Gordis, 2000; Wdak and Finkelhor, 1998). In fact, many families in which domestic violence is present, struggle with multiple problems, including poverty, substance abuse and exposure to other forms of violence.

Cognitive implication of child maltreatment includes difficulties in learning and in school performance. Many studies on causes of poor academic performance have consistently stressed the abused, maltreated, or neglected child on the average score lower on cognitive measures and demonstrative lower school achievement when compared with non abused peers of similar socioeconomic backgrounds (Vondra, Barnett and Cicchetti, 1990). Youngster with caring parents or caregivers learn to view themselves as worthy lovable and successful in school - related and cognitive tasks. However, children of uncaring caregivers may see themselves as unworthy of love or caring and incompetent in school performance (Barnett, Vondra and Shonk, 1996). The detrimental characteristics of abusive and neglectful parenting often lead to loss of self esteem and a lack of motivation to succeed at school (Lowenthal, 1998). At a very early age, maltreated child exhibit difficulties in selfesteembehaviour and adaptation to their environments. Abused toddlers respond more negatively, in contrast with non-abused peers, to their miner images and make fewer positive statements about themselves (Barnett, 1997).

The neglected group of maltreated children appeared to display the most severe problems in a number of studies. They were the last successful on cognitive tasks in class compared with the other types of maltreated children (Eckenrode, Laird and Doris, 1993; Mash and Wolfe, 1991). They are also inattentive, and apathetic, and they had difficulty in concentrating on cognitive tasks. A major reason for their poor performance could have been the lack of stimulation that the children received in their homes due to poor quality and erratic living conditions. The effects of their environments became more obvious at school because the children lacked opportunities to learn the necessary social and cognitive skills for school success.

At later school age, a number of studies demonstrate that all types of maltreated children demonstrated more cognitive difficulties and were considered more at risk for school failure and dropping out than their nonmaltreated classmates (Kurtz, Gaudin, Wodarski, and Howing, 1993; Reyome, 1993). The abused youngsters were rated by their teachers as more overactive, inattentive, impulsive, and disorganized than their non-abused classmates. They appeared less motivated to achieve at school and had difficulty learning.

\section{Statement of the Problem}

Times without number, there have been public outcry including media campaign against the prevalent exposure of children to this avoidable social misfortune called child maltreatment. When one goes out, one sees children engaged in petty-trading and street begging, while some hawk for their parent and guardians when they should be laying a solid foundation for the future. One reads about rape of children in the newspaper. One also sees cases of child prostitution in order to get money. Parent leave their children at home uncatered for and run after money making, there are also cases of child battering by some parents.

In a developing country like Nigeria, some socio-economic problems militate against the survival, development and protection of child. There is deprivation of basic emotional need largely due to parental 
absence from home in pursuit of economic survival. Poverty could lead to behaviours or rejection, intolerance, discrimination, deprivation, marginalization, cruelty and maltreatment towards children.

In school, one observed student who are affected with anxiety, depression, passive or withdrawal behaviour. Some of the student engage in aggressive, destructive and in appropriate acts or delinquent behaviour. One sees neglected children stealing or begging for food, students not coming to schools regularly and student sleeping during lessons almost all the time. Some seek inappropriate affection from offers. All these type of negative behaviours are wide spread in the country and they usually affect students' academic performance.

\section{General Objective}

The overall objective of this study was to determine the effect of child maltreatment on the academic performance of senior secondary school students in Ibadan, Nigeria.

\section{Literature Review}

Child maltreatment and neglect are becoming universal phenomena in the current world societies despite the fact the child's rights are being recognized and even to some extent, protected by legislations and constitutions in many countries of the world. Child maltreatment has been defined by the African network for the prevention and protection against child abuse and neglect (ANPPCAN) as the intentional and unintentional acts which endanger the physical, health, emotional, moral and the educational welfare of the child. Abuse of a child is anything that causes injury or puts the child in danger of physical injury. Child abuse can be physical (such as burns or broken bones), sexual (such as touching of private parts or incest), or emotional (such as belittling or calling the child names). Hopper (2004) also described child abuse as any act of maltreatment or subjection that endangers a child's physical, emotional and health development.

Child abuse and neglect consists of any acts of commission or omission by a parent or other caregiver that results in harm, potential for harm, or the threat of harm to a child (0-18 years of age) even if the harm is unintentional (Gilbert, Spatz, Widom, Braone, Fergusson, Webb,and Janson, 2009). The five main types of child maltreatment are: physical abuse, sexual abuse, emotional maltreatment, neglect, and witnessing domestic violence. Evidence suggests that different types of abuse and neglect rarely occur in isolation and children who experience repeated maltreatment often experience multiple forms of abuse (Higgins, 2004).

Gelles (1997), affirmed that child maltreatment include not only physical assault but also malnourishment, abandonment, neglect, emotional abuse and sexual abuse. According to Mba, (2002), prominent form of child abuse in Nigeria are child battering, child labour, child abandonment, neglect, teenage prostitution, early marriage and forced marriage, many abused children were unwanted in the first place and turned out to be a severe burden on their emotionally immature or impoverished parents. Odey (1993), stated that children from poor homes are more vulnerable to abuse and Todd (2004), in his support said that Nigeria, which is are known corrupt nation in Africa is heading towards a dangerous poverty where her teeming population does not have enough food for healthy living.

Although child maltreatment occurs in Nigeria, it has received little attention. This is probably due to the problems of malnutrition and infection. Another possible reason is the general assumption that in every African society, the extended family system always provides love, care and protection to all children. Yet there are traditional child rearing practices which adversely affect some children, such as female genital cutting, purposeful neglect or abandonment of handicapped children, twins and triplets in some rural areas. These may be considered as the outcome of abnormal interactions of the child, parents/guardians and society. This also includes abandonment of normal infants by unmarried or very poor mother in cities, increased child labour and exploitation of children from rural in urban elite families. Oluwole, (2002) equally lamented when analyzing the situation of children which are being used for house helps i Nigeria. Child labour is the major obstacles to the achievement of education for all (EFA) and these results into a setback on the achievement of the world target of universal primary education by 2015.

Child abuse is a serious global problem that is deeply rooted in cultural, economic and social practices and occurs in a variety of ways and places. Aderinto and Okunola, (1998) equally recorded that some children 
reported that they were pushed into street hawking for maintenance needs of the family. That means that they are the breadwinners of their various families at their early age. It is a common sight in major parks and streets in Nigeria to see children of school age between 6-16 years as bus/taxi mates, hawking wares, pushing trucks for money or begging for money when they are supposed to in the classroom learning in the schools. All these point to the fact that the worst hit groups are children who are at the risk of diseases, exploitation, neglect and violence.

Children and young people are affected by abuse and neglect in various ways. Outcomes of abuse may range from mild symptoms to debilitating and life-threatening conditions (Runyon and Kenny, 2002). Factors that may affect the way in which abuse and neglect affects children and adolescents include:

- the age and developmental status of the child when abuse occurred;

- the severity of maltreatment;

- the frequency and duration of maltreatment;

- the relationship between the child and the perpetrator; and

- the type(s) of abuse/neglect.

Any maltreatment of a child may lead to damaging adverse consequences; however, research indicates that chronicity and experiencing multiple types of abuse and neglect are related to greater maladjustment and negative outcomes for children (Arata, Langhinrichsen-Rohling, Bowers, and O'Farrill-Swails, 2005; Ethier, Lemelin, and Lacharite, 2004; Frederico, Jackson, and Black, 2008; Higgins and McCabe, 2001). Research on the relationship between different types of abuse and neglect is limited. However, a review by Higgins and McCabe, (2001) found that different types of abuse were significantly correlated (i.e.,children experienced more than one type of maltreatment). This co-occurrence was particularly common between physical abuse and other types of maltreatment. A child is physically abused if he/she is beaten up too often raped or over-used in the home on the farm or in the factory.

Chronic abuse and neglect can be defined as "recurrent incidents of maltreatment over a prolonged period of time" (Bromfield, Gillingham, and Higgins, 2007). Chronic experiences of child abuse and neglect occurring over different developmental periods can have a profound and exponential impact on a child's life (Frederico; Jackson; and Black, 2008; Miller, 2007). In associating child abuse and neglect with negative consequences, it is important to consider a child's abuse history rather than one isolated episode of abuse.

Research investigating the effect child abuse and neglect has on overall physical health has largely focused on outcomes in adulthood. However, data from the Longitudinal Studies of Child Abuse and Neglect (LONGSCAN) in the United States has indicated strong associations between abuse/neglect and health problems in children/adolescents (Flaherty, et al., 2006 and 2009). Flaherty, et al. (2006) found that exposure to one adverse experience doubled the odds of children having overall poor physical health at the age of 6 years, and tripled them if children had experienced four or more adverse experiences. A further study by Hussey, Chang, and Kotch (2006) found that all types of abuse and neglect were associated with 8 of 10 major adolescent health risks. A common form of abuse affecting the health of babies is shaken baby syndrome. Health problems resulting from shaken baby syndrome may include brain damage, spinal cord injuries, hearing loss, speech difficulties and even death (Child Welfare Information Gateway, 2008).

Children affected by neglect tend to be more isolated at school compared to other groups of children and have difficulty making friends (Hildyard and Wolf, 2002). Neglected children may also display aggressive and disruptive behaviour; however, externalizing behaviour problems are more closely associated with physical and sexual abuse or witnessing domestic violence (Hildyard and Wolf, 2002; Holt, Buckley, and Whelan, 2008). Inappropriate sexualized behaviour is also linked with abuse and neglect, and most commonly with sexual abuse and exposure to highly violent and sexualized environments (Corby, 2006; Merrick, Litrownik, Everson, and Cox, 2008).

Despite the growing national and international concern on child work, controversy exists among stakeholders, scholars and policy makers concerning the variables which influence family decisions to set school children at work for the purposes of augmenting family income and the effects on school achievement. Testing the luxury axiom of Basu and Van (1998) within the context of schooling that a family will withhold its children from schooling if it falls into poverty, Ray (2000) found this to be true for Pakistan but false in the case of Peru especially for girls. The case of Peru had earlier been documented by Patrinos and Psacharopoulos, (1997) where it was reported that children usually combine work with schooling. Ray (2000) went further to report that factors 
such as age and sex of children, number of children in the household, number of adults in the household, gender of household head, the education of parents and the wages of the parents contribute to family decision on children's work. Ray's (2000) and other studies on the involvement of children in economic activities have concentrated on the premise that parents rely on children to bail them out of poverty and that children's labour supply equation is partly a function of wage plus other family and community characteristics.

Children had always worked in the Nigerian society. Before the advent of modern economy, male children have always accompanied their fathers to the farm with the farm implements built to size and girls assisted their mothers in selling farm products and also with domestic chores. When education was introduced in the country, it was common practice for boys to combine farm work with schooling and school girls continued to assist their parents in the market place. Every member of the family must participate in family work to the extent of his/her age and ability. The point therefore seems to be that when children work, it is not necessarily due to the family poverty as shown by Basu and Van (1998) or credit market imperfections reported by Parker and Skoufias (2002) or a discounting of the value of education which according to Becker (1991) proposition that children's work may be a response to a trade-off between returns to and cost of education. Indeed, Dumas (2007) captures the description of the situation better when she observed that rather than being wage earners, most working children are more likely to work with their own parents. Indeed a large number of Nigeria's well educated present and past leaders worked while schooling during their youth.

\section{Theoretical Framework}

For better understanding of the effect of child maltreatment on academic performance of students, single parenthood and divorce has been discovered as a major factor causing child abuse and maltreatment. The theory of relative deprivation has been used to explain this phenomenon.

\subsection{Relative Deprivation Theory}

The Relative Deprivation Theory proposed by Gurr, (1990), lends credence to conflict handling in the home. According to Gurr, (1990) relative deprivation refers to perceived discrepancy between value expectation (resources to which one feels entitled) and value capabilities (resources which one feels capable of acquiring and keeping). The greater the average degree of perceived discrepancy between expected and value capabilities, the greater the intensity and scope of relative deprivation among members of same collectivity and the greater the potential for collective violence. He explained further that violence (a manifestation of conflict with physical, psychological or structural hurt), in this situation, occurs when an individual or group makes a comparison with others (perceived to be the same class or status with them) and they feel less measurable, due to deprivation of opportunities or resources they are equally entitled to within the system. When their attempts to meet up are thwarted, frustration sets in and they are most likely to strike at the source of frustration (Gurr,1990).

When parents or couples are divorced, researches have shown that the children are inclined to live with any of the partners or at times shared among the couples. The resultant effect is that the children from earlier ages are subjected to all forms of abuse. They are exposed to child labour, hawking, domestic violence etc. These in most cases serve as the means for augmenting family economic survival.

Adolescents like young children, experience considerable initial emotional pain and anger when their parents' divorce. However, they are usually better able to accurately assign responsibility for the break-up, to resolve loyalty conflicts, to more effectively cope with economic changes, and to deal with a new family structure than young children. The older adolescents may also be able to take advantage of available support systems to deal with the additional stresses (Hetherington, Stanley-Hagan and Anderson, 1999). It has been revealed that many broken-home-effected adolescents experience premature detachment from their parents. Many of these children become involved in antisocial groups and activities with disastrous outcomes. Older adolescents, because they have more self-confidence and resources, may confront and question some aspects of family function and roles that younger children would not(Hetherington and Anderson, 1999). Hence, children from divorce homes or single parenthood are denied better opportunities, abused and maltreated and these have negative effects on their academic performance. 


\section{Methodology}

The study employed the use of descriptive research design. The population of study consist of male and female. Students in senior secondary classes (SS1 - SS3) in Ibadan. Simple random sampling technique was used to select Ibadan South-West and Ibadan North Local Government Areas, out of the eleven Local Government Areas in Ibadan metropolis. From each of the two local governments selected, random sampling was further used to select three senior secondary schools from each to give a total of six secondary schools. From each school selected, 90 students (30 students from each arm SS1-3) were selected to give a total of 540 respondents.

A well structured questionnaire containing two sections was used as an instrument for data collection. Section A contain information on the personal background of respondents. Section B measures economic status of senior secondary school students, adapting Ariko (2009) factors influencing low academic performance of pupils scale in rural primary schools in Uganda. This include the present student/parent economic situation that affect the academic performance of student.

Respondents English and Mathematics results were used for the academic performance. Section $B$ is with options of response: Strongly Agree $=1$, Agree $=2$, Disagree $=3$, Strongly Disagree $=4$. Data was analyzed using simple percentage and multiple regression analysis (ANOVA), hypotheses tested at 0.05 level of significance.

\section{Analysis and Results}

Data collected by the use of questionnaire are analysed as follows:

Table 1:Demographic analysis of respondents

\begin{tabular}{|l|c|c|}
\hline Item & Frequency & Percentage \\
\hline Class: & & 35.9 \\
\hline SSS 1 & 184 & 32.8 \\
\hline SSS 2 & 168 & 31.3 \\
\hline SSS 3 & 160 & \\
\hline Age: & & 25.2 \\
\hline < 15years & 129 & 74.2 \\
\hline 15-18years & 380 & 0.6 \\
\hline >18years & 3 & \\
\hline Sex: & & 46.1 \\
\hline Male & 236 & 53.9 \\
\hline Female & 276 & 6.3 \\
\hline Parents' marital status: & & 85.4 \\
\hline Single & 32 & 4.7 \\
\hline Married & 437 & 3.7 \\
\hline Divorced & 24 & \\
\hline Widowed & 19 & 3.3 \\
\hline Father's education: & & 6.4 \\
\hline No formal education & 17 & 33.6 \\
\hline Primary education & 33 & 56.6 \\
\hline Secondary education & 172 & 3.9 \\
\hline Tertiary education & 290 & 50.2 \\
\hline Mother's Education: & 257 & \\
\hline No formal education & 185 & \\
\hline Primary education & & \\
\hline Secondary education & & \\
\hline Tertiary education & & \\
\hline Father's occupation: & & \\
\hline Trading & & \\
\hline & & \\
\hline
\end{tabular}




\begin{tabular}{|l|c|c|}
\hline Public servant & 113 & 22.1 \\
\hline Artisan & 45 & 8.8 \\
\hline Others & 209 & 40.8 \\
\hline Mother's occupation: & & \\
\hline Trading & 272 & 53.1 \\
\hline Public servant & 82 & 16.0 \\
\hline Artisan & 46 & 9.0 \\
\hline Others & 112 & 21.9 \\
\hline Size of the family: & & \\
\hline $3-4$ & 169 & 33.0 \\
\hline $3-5$ & 185 & 36.1 \\
\hline $3-6$ & 158 & 30.9 \\
\hline
\end{tabular}

Majority of the students used for the study were SSS 1 with 184 (35,9\%), their mean age ranges from 15 to 18year and were mostly females (Table 1).

The marital status of their parents shows that $85,4 \%$ are married, the singles and widowed have $6,3 \%$ and 3.7 respectively. A good number of parents have acquired good education, for fathers $56,6 \%$ have acquired tertiary education, while in the mothers, 50,2\% have acquired secondary education.

In terms of occupation of parents, greater number of males and females engage in trading with 28.3 and 53.1 per cent.

\subsection{Hypothesis}

There is no significant relationship between Child Maltreatment and Academic Performance

Table 13: Effect of Child Maltreatment on Academic Performance

\begin{tabular}{|l|l|l|l|l|l|l|}
\hline Variable & Mean & Std. Dev. & $\mathrm{N}$ & $\mathrm{r}$ & $\mathrm{P}$ & Remark \\
\hline Child Maltreatment & 23.4941 & 3.8009 & 512 & .535 & .000 & Sig. \\
& 22.3711 & 5.3438 & & & & \\
\hline Academic Performance & & & & & & \\
\hline
\end{tabular}

It is shown in the above table that there was significant relationship between Child Maltreatment and Academic Performance $(r=.586, \mathrm{~N}=512, \mathrm{P}<.05)$. Null hypothesis is rejected. This means that there is significant relationship between the child maltreatment and academic performances.

\section{Discussion}

The result of the test of the hypothesis is predicated upon the fact that Child abuse and neglect may lead to a wide range of adverse consequences for children and adolescents. Although specific types of abuse are more closely related to some adverse outcomes than others; for example, the links between physical abuse and violent or aggressive behaviour. However, experiencing chronic and multiple forms of abuse increases the risk of more damaging and severe consequences for children and young people. This study shows the link between child maltreatment and academic performance of young people. The experiences ranged from unpleasant, common acts of conflict such as being yelled at or spanked, to being insulted, threatened, neglected physically or emotionally, and to the relatively less common experiences of sexual abuse. These factor led to poor academic performance on affected students. This finding supported Mill's (2004) research which demonstrated that abused and neglected children perform less well on standardized tests and achieved poorer school marks, even when socio-economic status and other background factors are taken into account. 
This finding is supported by that of Kurtz et al, (1993) in two studies that compared the characteristics of the physically abused, sexually abused, and neglected school-age children. The physically abused pupils displayed significant school problems. Their performances were poor in all academic subjects but especially in mathematics and language. They appeared to be underachievers and were more likely to be restrained than their non-maltreated peers. They were at risk of dropping out of school.

\section{Conclusion}

As has been read from the study, child maltreatment or abuse is a serious impediment to academic performance of students. There are certain behaviours or acts which are child abuse exhibited by the adults unknowingly, which affects the child. Majority of the abused children are from the poor homes. Education on child's right should be included in the school curriculum, where the children will have the opportunity of being educated of their rights.

As a way of eradicating poverty in the populace, the government should intensify efforts in the poverty eradication programme to help parents have very good foundation for the proper upbringing and education of the children.

\section{References}

Aderinto, A. A. and Okunola, R. A. (1998), Pull and sustaining factors of child labour in Nigeria. Ife International Journal. Vol: 6, No: 1, pp. 178-184.

Alokan, F. B. (2010), The correlation between parent's educational status and child house. Humanity and social science journal. Vol: 5, No: 1, pp. 73.

Arata, C. M.; Langhinrichsen-Rohling, J; Bowers, D; and O'Farrill-Swails, L. (2005), Single versus multi-type maltreatment: An examination of the long-term effects of child abuse. Journal of Agrression, Maltreatment and Trauma. Vol: 11, No: 4, pp. 29-52.

Barnett, O. (1997). The effects of early intervention on maltreating parents and their children. Guralnick, M.J, The effectiveness of early intervention; pp 147-170. Baltimore MB: Brookes. (ERIC Document No. ED414694).

Battle, and Lewis, M. (2002). The increasing significance of class: the relative effects of race and socio economic status on academic achievement. The journal of Poverty. Vol. 6, No 2, pp 21-35.

Becker, G.S., and Tomes, N. (1979). An Equilibrium Theory of the Distribution of Income and Intergenerational mobility. Journal of Political Economy, Vol: 87, 1153-1189.

Bromfield, L. M., Gillingham, P., and Higgins, D. J. (2007). Cumulative harm and chronic child maltreatment. Developing Practice, Vol: 19, pp. 34-42.

Child Welfare Information Gateway, (2008). What is child abuse and neglect? Factsheet. http://www.childwelfare.gov Lpubs/factsheets/whatiscan.cfm.

Corby, B. (2006). Child abuse: Towards knowledge base (3rd Ed.), Berkshire: Open University Press,

Eckenrode, J., Laird, O.MM and Doris, J. (1993). School performance and disciplinary problems among abused and neglected children. ERIC Journal No. EJ461704. Vol. 29, No 1, pp. 53-63.

Ethier, L; Lemelin, J. P; and Lacharite, C. (2004). A longitudinal study of the effects of chronic maltreatment on children's behavioral and emotional problems. Child Abuse and Neglect. Vol: 28, pp. 1265-1278.

Frederico, M., Jackson, A., and Black, C. (2008). Understanding the impact of abuse and neglect on children and young people referred to a therapeutic program. Journal of Family Studies. Vol: 14, pp. 342-361.

Gelles, R. J. (1997). Intimate Violence in Families, 3rd edition, Thousand Oaks

Gilbert, R.; Spatz Widom. C; Browne, K; Fergusson, D; Webb, E; and Janson, J. (2009). Burden and consequences of child maltreatment in high-income countries. The Lancet. Vol: 373, pp. 68-81.

Gurr R. T. (1990). Why Men Rebel, in "Decisions, Decisions, Decisions", Psychology Today in Conflict and Conflict Management by Kenneth Thomas. (1991). Vol: 5, pp. 51-54; 86-88.

Higgins, D. (2004). Differentiating between child maltreatment experiences. Family Matters. Vol: 69, pp. 50-55.

Higgins, D. and McCabe, M. (2001). Multiple forms of child abuse and neglect: Adult retrospective reports. Aggression and Violent Behaviour. Vol: 6, pp. 547-578.

Hildyard, K. L. and Wolf, D. A. (2002). Child neglect: Developmental issues and outcomes. Child Abuse and Neglect. Vol: 26, No: 6-7, pp: 679-695.

Holt, S.; Buckley, H.; and Whelan, S. (2008). The impact of exposure to domestic violence on children and young people: A review of the literature. Child Abuse and Neglect. Vol: 32, pp. 797-810. 
Imtionde, H.O, Aluede O. and Oboite W. (2008). Domestic violence and adolescent psychological functioning among secondary school students in the Benin metropolis of Nigeria. European Journal of Educational Studies. Vol: 1 , No: 1, pp. 1-2.

Kutz, P.D, Gaudin, J.M, Wodarski, J.S. and Howing, P.T. (1993). Maltreatment and the school-aged child: School performance consequences. Child Abuse and Neglect (ERIC journal : No EJA72702). Vol: 17, No 5, pp 581-589.

Lowenthal, Barabara, (1998). Child maltreatment: Effect on development and learning. Clearing house on early education and parenting, Research center,

Margolin, G. and Wolfe, D.A. (2000). The effects of family and community violence onchildren. Annual review of psychology. pp, 51, 445-479.

Mash, E.J and Wolfe, D.A. (1991). Methodological issues in research on physical child abuse. A journal of criminal justice and behaviour. Vol. 18, No 1, pp. 8.29.

Mba, A.I. (2002). The Problem of Child Abuse in Nigeria. Conference proceedings. Pp 79-82.

Merrick, M; Litrownik, A; Everson, M; and Cox, C. (2008). Beyond sexual abuse: The impact of other maltreatment experiences on sexualized behaviors. Child Maltreatment. Vol: 13, No: 2, pp. 122-132.

Mills, C. (2004). Problems at home, problems at school: The effects of maltreatment in the home on children's functioning at school. An overview of recent research. London: National Society for the Prevention of Cruelty to Children, 2004, Retrieved 5 November. www.nspcc.org.uk/Inform/publications /Downloads/problemsathome _wdf48202.pdf

Miller, R. M. (2007). Cumulative harm: A conceptual overview. Melbourne: Department of Human Services, Retrieved 5 November 2011. www.cyf.vic. gov.au/data/ assets/ pdf_file/0010/43012/ececbestinterest_cumulative_harm.pdf.

Odey, S.T. (1993). Child labour. The Nigeria Chronicle. Vol: 29, No: 5, pp. 7.

Oluwole, G. (2002). House Helps and Madam. The Punch. Vol: 17, No: 12, pp. 55.

Osofsky, J.D. (1995). Children who witness domestic violence. Social Policy Report. pp. 9,1-16.

Ray, Rajin, (2000). Child Labor, Child schooling and their interaction with Adult labor: Empirical evidence for Peru and Pakistan. The World Bank Economic Review. Vol: 14, No: 2, pp 347-67.

Reyome, N.D, (1993). Medicine and psychotherapy: neurodevelopment and neurophysiology of trauma, pp.6, 13-20.

Runyon, M., and Kenny, M. (2002). Relationship of attributional style, depression, and post-traumatic distress among children who suffered physical or sexual abuse. Child Maltreatment. Vol: 7, pp. 254-264.

Todd, B. (2004). Assuring Food Nutrition Security in Africa by 2020. Washington DC: International Food and Policy Research Institute. 
